Editors' Note: In WriteClick this week, Dr. Muth recalls his elective experience at Moi Teaching Hospital in Kenya and expresses the importance of collaboration and partnerships between hospitals in resource-rich and resource-poor countries for the benefit of both students and patients. Discussion ensues among Drs. Romigi et al. and authors Silvestri et al. and St. Louis et al. regarding the most frequent sleep disorders found in myotonic dystrophy type 2 and how to study them.

INTERNATIONAL ISSUES: EXPANDING NEUROLOGIC EDUCATION TO RESOURCE-POOR COUNTRIES: LESSONS FROM MOI TEACHING HOSPITAL

Christopher C. Muth, Chicago: Cortez et al. ${ }^{1}$ should be commended for sharing their experiences at Moi Teaching Hospital and highlighting the challenges of providing neurologic care and education in a resource-limited setting. As a former medical student who participated in an elective at Moi Teaching Hospital and as a current neurology resident at a US institution, I feel compelled to underscore the importance of long-term institutional partnerships. These collaborations aid in the development of sustainable patient care and education initiatives in resource-poor countries. These partnerships foster alliance and encourage accountability among all parties and also facilitate international health exchange opportunities for trainees in both resource-rich and resource-poor countries. Lyons et al. ${ }^{2}$ recently reported that one of the major barriers to US and Canadian trainee participation in global health electives is a lack of formal partnerships with international sites. Given the increasing burden of neurologic illnesses in lowand middle-income countries and increasing globalization, neurologists from all countries and at all levels of training have a vested interest in cultivating mutually beneficial long-term partnerships between resource-rich and resource-limited institutions.

(C) 2014 American Academy of Neurology

1. Cortez MM, Wold JJ, Renner DR. International Issues: expanding neurologic education to resource-poor countries: lessons from Moi Teaching Hospital. Neurology 2014;82: e18-e20.
2. Lyons JL, Coleman ME, Engstrom JW, Mateen FJ. International electives in neurology training: a survey of US and Canadian program directors. Neurology 2014;82:119-125.

\section{RESTLESS LEGS SYNDROME AND DAYTIME SLEEPINESS ARE PROMINENT IN MYOTONIC DYSTROPHY TYPE 2}

Andrea Romigi, Fabio Placidi, Maria Albanese, Francesca Izzi, Claudio Liguori, Nicola B. Mercuri, Maria G. Marciani, Roberto Massa, Rome: We read with interest the WriteClick exchange between Silvestri et al. ${ }^{1}$ and Lam et al. ${ }^{2}$ Silvestri et al. highlighted that obstructive sleep apnea (OSA) is the most relevant sleep disorder in myotonic dystrophy type 2 (DM2), according to their home-based cardiorespiratory experience in 14 patients. They also refuted and we agree that OSA could be excluded by questionnairebased studies, as done by Lam et al. ${ }^{2}$ However, both these studies may have been biased by the lack of polysomnographic (PSG) data. We recently published a full PSG-controlled study of sleep and sleepiness in DM2 (PSG American Academy of Sleep Medicine type 2 followed by multiple sleep latency test and comprehensive subjective questionnaires) and compared our results to those obtained in DM1 and healthy controls. ${ }^{3,4} \mathrm{We}$ found impaired sleep efficiency in 12/12 patients with DM2, in association with OSA in 7/12 patients (58.3\%). Interestingly, 6/12 patients with DM2 (50\%) showed REM sleep without atonia (RSWA) with REM sleep behavior disorder (RBD) in $1 / 6$, confirming REM sleep dysregulation in myotonic dystrophies. ${ }^{5}$ OSA and RSWA are novel observations in DM2. OSA may represent a triggering factor. Although RSWA may represent a compensatory mechanism of OSA, it could be related in DM2 to the involvement of pedunculopontine and laterodorsal tegmental nuclei, which are critical modulators of RBD. ${ }^{5}$

\section{Author Response: Gabriella Silvestri, Maria Laura} E. Bianchi, Anna Losurdo, Giacomo Della Marca, Rome: The authors thank Romigi et al. for their comments about the WriteClick exchange between our group and Lam et al. ${ }^{1,2}$ We agree that full PSG is a more powerful tool to evaluate patients with myotonic dystrophy, who can present sleep-disordered breathing (SDB) and other sleep disorders including 
RSWA, RBD, and restless legs syndrome (RLS). However, in our study, ${ }^{1,6}$ we evaluated the occurrence of SDB in patients with DM2 by home-based cardiorespiratory monitoring, since SDB may worsen cardiorespiratory and cognitive functions, which are often impaired in these patients. Nevertheless, Romigi et al. ${ }^{3}$ raised an issue concerning the relationship between obstructive sleep apnea syndrome (OSAS) and RSWA; it would be interesting to evaluate if ventilatory treatment of OSAS in patients with DM2 could also be beneficial for RSWA and RBD if these conditions were pathologically related to OSAS as these authors suggest. Moreover, their study confirms that SDB is the most relevant sleep disorder in patients with DM2. ${ }^{3}$

Author Response: Erik K. St. Louis, Rochester, MN; Erek M. Lam, Pittsburgh; Paul W. Shepard, Minneapolis: The authors thank Romigi et al. ${ }^{3}$ for their comments concerning our study of sleep disturbances in DM2 and previous WriteClick exchange with Silvestri et al. ${ }^{1}$ concerning comorbid obstructive sleep apnea (OSA) in DM2. We applaud their prospective PSG study of genetically confirmed DM $2,{ }^{3}$ in which they found comparably frequent OSA, hypersomnia, and sleep-disturbing pain symptoms similar to other reports. ${ }^{1,2,7}$ They also found more frequent periodic leg movements of sleep (PLMS) and RSWA than a convenience healthy control sample. ${ }^{3}$ We did not definitively exclude comorbid sleep apnea in DM2, but rather emphasized that RLS was a more frequent sleep-disturbing comorbidity in DM2 than OSA symptoms, which were comparably frequent between DM2 and community controls. Romigi et al. did not assess subjective RLS symptoms or potential association of PLMS with disturbed sleep, and provide no information regarding medical or psychiatric comorbidities or comedications, which were factors carefully controlled for in our study. It is unclear whether these factors could be alternative explanations for frequent RSWA in their sample. ${ }^{8}$ Future large DM2 cohort studies are necessary to determine the frequency and range of sleep disturbances in this pleiotropic systemic disorder.

(C) 2014 American Academy of Neurology

1. Silvestri G, St. Louis EK, Bianchi MLE, et al. Restless legs syndrome and daytime sleepiness are prominent in myotonic dystrophy type 2. Neurology 2014;82:283284. Letter.

2. Lam EM, Shepard PW, St Louis EK, et al. Restless legs syndrome and daytime sleepiness are prominent in myotonic dystrophy type 2. Neurology 2013;81:157-164.

3. Romigi A, Albanese M, Placidi F, et al. Sleep disorders in myotonic dystrophy type 2: a controlled polysomnographic study and self-reported questionnaires. Eur J Neurol 2014; 21:929-934.

4. Romigi A, Izzi F, Pisani V, et al. Sleep disorders in adultonset myotonic dystrophy type 1 : a controlled polysomnographic study. Eur J Neurol 2011;18:1139-1145.

5. Romigi A, Albanese M, Liguori C, et al. Sleep-wake cycle and daytime sleepiness in the myotonic dystrophies. J Neurodegener Dis 2013; vol. 2013, Article ID 692026; doi: 10.1155/2013/692026.

6. Bianchi ML, Losurdo A, Di Blasi C, et al. Prevalence and clinical correlates of sleep disordered breathing in myotonic dystrophy types 1 and 2. Sleep Breath Epub 2013.

7. Shepard P, Lam EM, St Louis EK, Dominik J. Sleep disturbances in myotonic dystrophy type 2. Eur Neurol 2012; 68:377-380.

8. McCarter SJ, St. Louis EK, Boeve BF. REM sleep behavior disorder and REM sleep without atonia as an early manifestation of degenerative neurological disease. Curr Neurol Neurosci Rep 2012;12:182-192.

\section{WriteClick: Rapid Online Correspondence}

Have a comment on a recent Neurology ${ }^{\circledR}$ article you would like to share? Now it is easier and more convenient. Neurology.org has launched WriteClick on the home page and sidebars of each article to encourage remarks and debate among users.

WriteClick is restricted to comments about studies published in Neurology within the last eight weeks.

Learn more at http://www.neurology.org/letters 


\section{Neurology}

\section{Restless legs syndrome and daytime sleepiness are prominent in myotonic dystrophy type 2}

Andrea Romigi, Gabriella Silvestri, Erik K. St. Louis, et al. Neurology 2014;83;572-573

DOI 10.1212/01.wnl.0000453225.02417.cf

This information is current as of August 4, 2014

\section{Updated Information \& Services}

References

Permissions \& Licensing

Reprints including high resolution figures, can be found at: http://n.neurology.org/content/83/6/572.2.full

This article cites 6 articles, 2 of which you can access for free at: http://n.neurology.org/content/83/6/572.2.full\#ref-list-1

Information about reproducing this article in parts (figures,tables) or in its entirety can be found online at:

http://www.neurology.org/about/about_the_journal\#permissions

Information about ordering reprints can be found online: http://n.neurology.org/subscribers/advertise

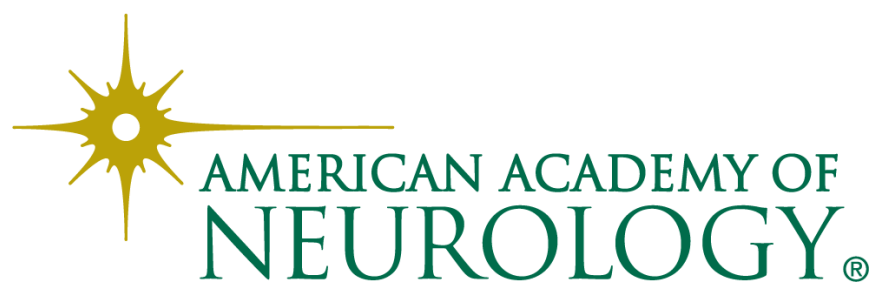

